\title{
Air Quality Monitoring and Purification Devices: A Review
}

\author{
Praveen Thakran, Malla Sainadh Ram Narsimha, Nisha Charaya, Dr. Karamjit Kaur
}

\begin{abstract}
Air quality has been degrading due to increase in vehicles and industrial activities. These industrial activities and vehicles cause most of the air pollutants as gases, but some are very tiny solid particles, such as dust, smoke. Most commonly detected air pollutants are Sulphur Dioxide $\left(\mathrm{SO}_{2}\right)$, particulate matter, Hydrocarbons (HC), Lead, Carbon Dioxide $\left(\mathrm{CO}_{2}\right)$ and Carbon Monoxide (CO), Nitrogen Oxides $\left(\mathrm{NO}_{\mathrm{x}}\right)$, and smog. These air pollutants affect both the indoor and outdoor air. The indoor air is more polluted, due to the release of the air borne chemicals while cooking and from furniture. The polluted air is unsafe for human health. So, the need of an indoor automatic air purifier arises. This paper presents a thorough study of different techniques and models developed to monitor the air quality and hereby control the air purifier system.
\end{abstract}

Keywords: Pollution, indoor air, purifier, air quality.

\section{INTRODUCTION}

Air is made up of gases such as Nitrogen, Oxygen, Carbon Monoxide and traces of some rare elements. Any change in the natural composition of air may cause grave harm to life forms on earth, this is air pollution. It is the presence of one or more contaminants in the atmosphere such as gases in a quantity that can harm humans, animals and plants.

It is widely known that the atmosphere has been highly polluted over the recent years, and thus more and more people start to take this subject seriously. These pollutants are emitted from both man-made and natural sources.

\section{Manuscript received June 7, 2020}

Praveen Thakran, UG Scholar, Department of Electronics \& Communication Engineering, Amity University Haryana, Gurugram, India (email: thakranparveen2@gmail.com)

Malla Sainadh Ram Narsimha, Department of Electronics \& Communication Engineering, Amity University Haryana, Gurugram, India

Nisha Charaya, Assistant Professor, Department of Electronics \& Communication Engineering, Amity University Haryana, Gurugram, India

Dr. Karamjit Kaur, Associate Professor, Department of Electronics \& Communication Engineering, Amity University Haryana, Gurugram, India
Pollutants are classified as two categories: primary and secondary pollutants. Primary pollutants are released directly into the atmosphere. Secondary pollutants are produced when the primary pollutant reacts with other atmospheric chemicals. Therefore, most of the existing air-quality monitoring systems aim to detect harmful gases which are the common resources of pollution, such as carbon monoxide $(\mathrm{CO})$, carbon dioxide $\left(\mathrm{CO}_{2}\right)$ and formaldehyde $\left(\mathrm{CH}_{2} \mathrm{O}\right)$ as well as a mixture of smoke and fog, i.e. smog (PM2.5). Air pollutants are measured in Parts per Million (ppm) or $\mathrm{ug} / \mathrm{m}^{3}[1]$. It is commonly believed that the outdoor air quality is worse than indoor air quality. But in recent studies it is known that levels of indoor air pollutants is 3 to 5 times higher than outdoors. The indoor air quality is not the same in every area, monitoring each area is also not an easy task. Government with citizens are looking for way to challenge the threat of air pollution in many ways. Air filters were developed, using very few components like fan with a filter attached behind it. Later, many different filtration technologies are developed. Now, mobile apps are being developed to do functions like reporting air quality levels, air quality monitoring in an area, and forecasting etc. When the government's air quality monitoring system gives an alarm about the bad air quality, then only people usually turn on their air purifiers and take preventive measures[2]. Figure 1 shows a general air purifier.

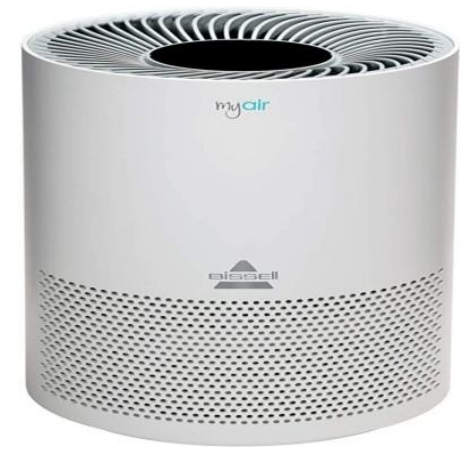

Fig 1: A general air purifier[3]

\section{LITERATURE REVIEW}

Pollution has been one of the serious issues in recent years. It has drawn attention of researchers to develop solutions to overcome this problem. In 2013, Ching Ming Lai and Ming Ho Pan proposed an ionization based air 


\section{Air Quality Monitoring and Purification Devices: A Review}

purifier. In this model, a negative ion generating circuit with $8 \mathrm{kV} / 4 \mathrm{kV}$ dual-output was developed, which generated the high electric field to ionize the air. With this number of active particles in the air increased, which reacted with the exhaust gas and made the air cleaner. The circuit analysis and results were presented and a prototype was realized to verify the performance[4]. Simone Brienza and Andrea Galli in 2015, proposed a low-cost sensing system for cooperative air quality monitoring. They developed a model to know the real time concentrations of polluting gases and deployed it in various cities. Data obtained from sensors were sent to uSense database via internet which were accessed by users. The main idea of the uSense was to make people aware of the air quality in their surroundings, so that preventive measures could be taken[5].

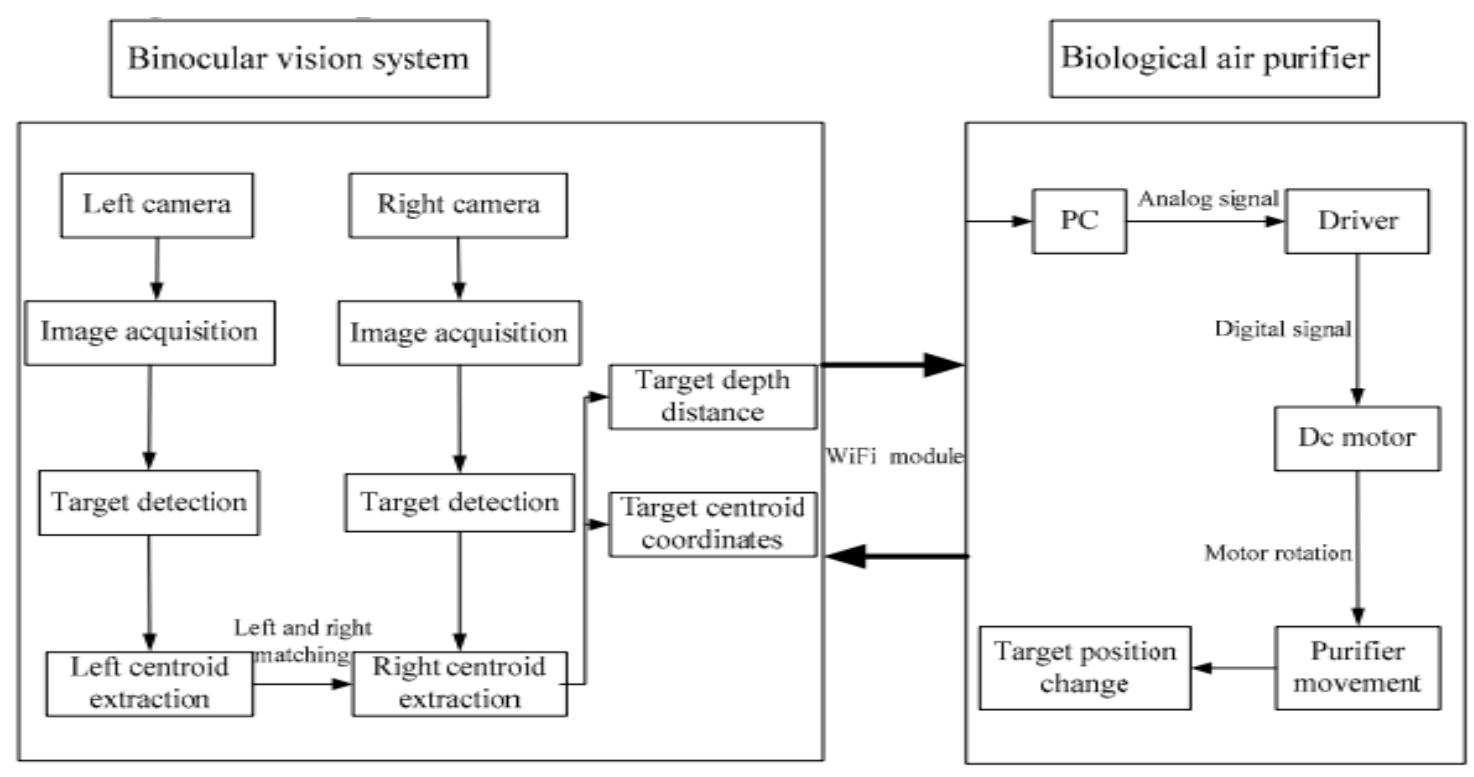

Fig 2: General framework of Indoor Mobile Biological Purifier[5]

In 2016, Liang Fan, Chen Hongdou proposed an indoor mobile biological air purifier with pedestrian tracking system. Mobile biological air purifier tracked pedestrians, monitored various pollutants around pedestrian environment, and improved air quality.Figure 2 shows the general framework of indoor mobile biological air purifier. Various algorithms were adopted to check its performance. The tracking system was established, by adopting the Harr + Adaboost algorithm for realizing detection and CamShift algorithm for tracking of pedestrian and mobile biological air purifier filter. The Kalman filter was deployed to predict the next position improving the effect of purifier detection and tracking. The experimental results showed that the system could realize mobile biological air purifier tracking pedestrians accurately, in real time[6].

HakJoon Kim and Bangwoo Han in 2017, proposed a model of air purifier using an activated carbon fibre. They developed a novel electrostatic air purifier using, a carbon fibre brush combined with a metallic collection rod and an activated carbon fibre (ACF) sheet. This improved the indoor air quality in cars. The ACF sheet was used to apply electrostatic forces, which moved the charged particles towards the collection rod and simultaneously absorb gas. Performance of the purifier was compared to a commercial purifier with a HEPA filter, activated carbon pellets, and alumina balls. The clean air delivery rate (CADR) of the novel electrostatic air cleaner was $0.219 \mathrm{~m}^{3} / \mathrm{min}$ which is $35 \%$ higher than the HEPA filter. Now, for the ESP, air cleaner test gases were $0.25,0.19$, and $0.19 \mathrm{~m}^{3} / \mathrm{min}$, respectively. which indicated, the novel ESP air cleaner reduced the gases by $308 \%$, 204\%, and $327 \%$, respectively, faster than commercial purifiers[7].

Alexi Delgado and Hugo Flor in 2017, developed a project to select the best air purifier using AHP. In this project, they conducted a study to select the best air purifier equipment for an urban house. Threealternatives were proposed toevaluate the air purifier equipment: Bap1700, Bap600 and Bap706; which were ranked, basedon the criteria of scope, characteristics, and model. To carry out the selection using AHP, a panel of four experts were selected who determined the best air purifier equipment to be, Air Purifier Bap1700[8].

Manisha Sharma and Ajay Kumar in 2017, proposed a I2P air purifier with air quality monitoring device. In the project, they detected impurities using gas sensors. The sensors were connected to the Arduino was loadedwith code as per which the air purifier functioned. The harmful levels of pollutants were set up as limits in the code. If the limit exceeded then a buzzer sounded along with LCD display which gave the information that it's time to switch ON the filtering device[9].

In 2017, Xiao Qijun and Liu Chauying proposed, a design of control system for an intelligent air purifier and sweeper combined robot. It presented design of the hardware and software of control system. Themain function of the system was to design a control system for opening and closing of the door based upon the dust concentrationusing a stepper motor. The cooperative control between the purifier and the sweeping machine was based on the calculation of the dust thickness on the 
floor. The system hada high degree of intelligence to know dust concentration and clearance of air and floor[10].

Sanjay Shitole and Devika Nair in 2018, proposed Internet of Things (IOT) based Indoor Air Quality Improving System. This project was developed using indoor plants and Internet of things (IOT) based system to purify air quality. Air purification ability of plants like, SansevieriaTrifasciata and Chlorophytumcomosum plants were analysed in closed environment. These plants were re-silent and required very less maintenance. These indoor plants were installed in offices, houses for testing and could purify indoor air up to a good level. Results of the study concluded that, Sansevieriatrifasciata and

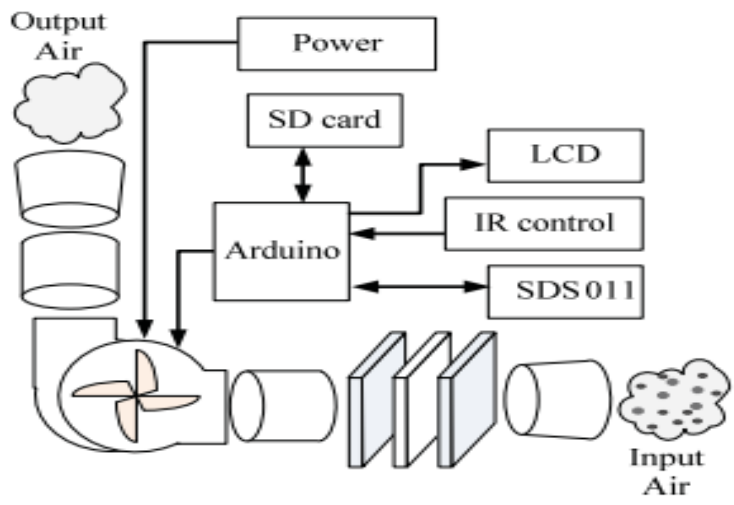

Fig 3: Portable Air Purifier[15]

Chlorophytumcomosum plants were effective and very low-cost solution to purify indoor air quality[11].

In 2018, Kennedy Okokpujie, EtinosaNoma-Osaghae proposed an air pollution monitoring system. This system was developed using Arduino microcontroller to monitor and analyse air quality in real time and log data to a remote server, keeping the data updated over the internet. Air quality measurements were taken based on the PPM (Parts Per Million) metrics and was analysed using Microsoft excel. The data was accessible through any mobile phone via cloud server[12].

Chun-Ming, Yi-Jun Liu in 2018, proposed a model for air quality monitoring by a wireless multi-gas sensing system which detected the concentration of three harmful compounds i.e. $\mathrm{CO}, \mathrm{CO}_{2}$ and $\mathrm{CH}_{2} \mathrm{O}$ along with $\mathrm{PM} 2.5$. A smart phone app was developed to show real-time data and for alerting users through $\mathrm{Wi}-\mathrm{Fi}$ or Bluetooth connection when the corresponding gas concentration was high. Because of the resource sharing scheme, the hardware developed was small and compact[13].

In 2018, Tanya Nanaiah and $\mathrm{K}$ Ambika proposed 'EnviDron' to purifuyair. The product developed was a drone that aimed to purify air by monitoring the amount of toxins and then filtering them out, thereby released relatively pure air. The single drone purified a very small percentage of air. The future of the project, lied in bringing a difference in the air quality as a whole, so swarm robotics can be used for this[14].

Marin BerovMarinov, DimitarLlivein 2019, proposed a Portable Air Purifier (PAP) with Air Quality Monitoring Sensor. Figure 3 shows a PAP device. The device was used to improve air quality in small spaces. The PM
(Particulate Matter) particle collection efficiency of the PAP (Portable Air Purifier) was examined for particlesin a test room, with a diameter in range 0.3-5 $\mu \mathrm{m}$ under different operating modes. The experiments showed good effectiveness in maintaining air quality. 
Air Quality Monitoring and Purification Devices: A Review

III. COMPARATIVE ANALYSIS

\begin{tabular}{|c|c|c|c|c|}
\hline AUTHORS(s) & YEAR & $\begin{array}{l}\text { TECHNOLOGY USED } \\
\end{array}$ & $\begin{array}{l}\text { Performance } \\
\end{array}$ & GAPS \\
\hline $\begin{array}{l}\text { Ching Ming Lai, Ming } \\
\text { Ho Pan }\end{array}$ & 2013 & Negative ion generating circuit & $\begin{array}{l}\text { Based on the reaction of exhaust } \\
\text { and active particles in air. }\end{array}$ & $\begin{array}{l}\text { Didn't show the } \\
\text { efficiency levels in } \\
\text { the results. }\end{array}$ \\
\hline $\begin{array}{l}\text { SimmoneBrienza, } \\
\text { Andrea Galli }\end{array}$ & 2015 & Gas sensors, $u$ Sensedatabase & $\begin{array}{l}\text { Aimed to make people aware about } \\
\text { the air quality. Gave these values to } \\
\text { local govt. }\end{array}$ & $\begin{array}{l}\text { People had to visit the } \\
\text { uSense domain, to see } \\
\text { data. No alerts were } \\
\text { given. }\end{array}$ \\
\hline $\begin{array}{l}\text { Liang Fan, Chen } \\
\text { Hongdou }\end{array}$ & 2016 & $\begin{array}{l}\text { Harr+ Adaboost, CamShift } \\
\text { algorithms and Kalman filter }\end{array}$ & $\begin{array}{l}\text { Tracked air quality for pedestrians, } \\
\text { improve the air quality outdoor. }\end{array}$ & $\begin{array}{l}\text { Couldn't provide } \\
\text { significant } \\
\text { purification, because } \\
\text { of outdoors. }\end{array}$ \\
\hline $\begin{array}{l}\text { Alexi Delgado, Hugo } \\
\text { Flor }\end{array}$ & 2017 & $\begin{array}{l}\text { Analytical Hierarchy } \\
\text { Process(AHP) }\end{array}$ & $\begin{array}{l}\text { Evaluated air purifier equipments } \\
\text { and determined the best out of } \\
\text { three. }\end{array}$ & $\begin{array}{l}\text { Didn't give further } \\
\text { suggestion on circuit } \\
\text { design. }\end{array}$ \\
\hline $\begin{array}{l}\text { Manisha Sharma, Ajay } \\
\text { Kumar }\end{array}$ & 2017 & $\begin{array}{l}\text { Gas sensors with Arduino } \\
\text { microcontroller }\end{array}$ & $\begin{array}{l}\text { Developed a semi-automated air } \\
\text { purifier,gavebuzzer when the levels } \\
\text { are high. }\end{array}$ & $\begin{array}{l}\text { The air purifier was } \\
\text { not automated. }\end{array}$ \\
\hline $\begin{array}{l}\text { HakJoon Kim, } \\
\text { Bangwoo }\end{array}$ & 2017 & $\begin{array}{l}\text { Based on electrostatic forces. } \\
\text { [A carbon fiber brush, metallic } \\
\text { collection rod, activated } \\
\text { carbon fiber sheet(ACF)] }\end{array}$ & $\begin{array}{l}\text { Based on novel Electrostatic forces, } \\
\text { gave better and faster results. }\end{array}$ & $\begin{array}{l}\text { Power consumption } \\
\text { was too high }\end{array}$ \\
\hline $\begin{array}{l}\text { Xiao Oijun, Liu } \\
\text { Chauving }\end{array}$ & 2017 & $\begin{array}{l}\text { A control system, } \\
\text { stepper motor, dust sensor }\end{array}$ & $\begin{array}{l}\text { Based on the dust thickness, the } \\
\text { purifier and sweeping machine } \\
\text { functioned. }\end{array}$ & $\begin{array}{l}\text { Focused only on dust } \\
\text { concentrations and } \\
\text { less on air } \\
\text { purification. }\end{array}$ \\
\hline $\begin{array}{l}\text { Sanjay Shitole, Devika } \\
\text { Nair }\end{array}$ & 2018 & $\begin{array}{l}\text { IOT based using Indoor } \\
\text { plants-Sansevieria Trifasciata and } \\
\text { Chlorophytumcomosum }\end{array}$ & $\begin{array}{l}\text { Indoor plants purified air up-to } \\
\text { good level at very low-cost. }\end{array}$ & $\begin{array}{l}\text { Needed ventilation to } \\
\text { survive, sometimes } \\
\text { not possible in co- } \\
\text { orperate offices. }\end{array}$ \\
\hline $\begin{array}{l}\text { Tanya Nanaiah, K } \\
\text { Ambika }\end{array}$ & 2018 & $\begin{array}{l}\text { Drones connected } \\
\text { with filters, sensors. }\end{array}$ & $\begin{array}{l}\text { Drone flew over, monitored quality } \\
\text { and purified air }\end{array}$ & $\begin{array}{l}\text { But was effective only } \\
\text { to small spaces that } \\
\text { too indoor. } \\
\text { Future scope lied in } \\
\text { developing swarm } \\
\text { bots for larger spaces. }\end{array}$ \\
\hline $\begin{array}{l}\text { Kennedy Okokpujie, } \\
\text { EtinosaNamo-Osaghae }\end{array}$ & 2018 & $\begin{array}{l}\text { Arduino microcontroller based, } \\
\text { remote server, Microsoft excel } \\
\text { spreadsheet for recording }\end{array}$ & $\begin{array}{l}\text { Analysed air quality in real time } \\
\text { and logged data to remote server } \\
\text { through cloud technology. PPM } \\
\text { metrics was used. Internet } \\
\text { connectivity is necessary to access } \\
\text { the data. }\end{array}$ & $\begin{array}{l}\text { System monitored the } \\
\text { data, but had no } \\
\text { purification part. }\end{array}$ \\
\hline Chun-Ming, Yi-Jun Liu & 2018 & $\begin{array}{l}\text { Gas sensor - Smart phone } \\
\text { App based Wi-Fi module. }\end{array}$ & $\begin{array}{l}\text { The gas concentrations were } \\
\text { measured and given to } \\
\text { microcontroller, } \\
\text { when the levels were high, users } \\
\text { were alerted through the App. }\end{array}$ & $\begin{array}{l}\text { Had no air } \\
\text { purification system } \\
\text { attached, only } \\
\text { monitoring and } \\
\text { alarming was there. }\end{array}$ \\
\hline $\begin{array}{l}\text { Marin BerovMarinov, } \\
\text { DimitarLliveLlive }\end{array}$ & 2019 & Sensors and microcontroller based. & $\begin{array}{l}\text { Portable air purifier to improve air } \\
\text { quality in small spaces. Used the } \\
\text { Particulate Matter metrics, showed } \\
\text { good effectiveness in small spaces. }\end{array}$ & $\begin{array}{l}\text { Not an automated } \\
\text { device. Effective only } \\
\text { on PM particles. }\end{array}$ \\
\hline
\end{tabular}

\section{CONCLUSION}

This paper presented a detailed study on Automated Air Purifier. From the study of various papers, it is clear that the focus was on indoor gases like $\mathrm{CO}, \mathrm{CO} 2, \mathrm{NOx}$ and the filtration was done using electrostatic forces, which consume lots of power. Few had monitoring systems, without air purifier whereas few were purifiers without monitoring system. However, an air purifier which is capable of monitoring the air quality continuously and automatically controlled by the collected data and a decision algorithm will be the complete solution to solve this problem.

\section{REFERENCES}

[1] https://www.gktoday.in/gk/primary-secondary-airpollutants/

[2] https://www.mana.md/indoor-air-vs-outdoor-air/

[3] https://images.app.goo.gl/DnmtK8uTZzpZ81WX6

[4] Ching Ming Lai and Ming Ho Pan, "Ionization based air purifier", Consumer Electronics (ISCE), IEEE 17th International Symposium, 2013.

[5] Simone Brienza and Andrea Galli, "Low-cost sensing system for cooperative air quality monitoring”, Sensors,12242-12259, 2015. 
[6] Liang Fan, Chen Hongdou, "Indoor mobile biological air purifier with pedestrian tracking system", Chinese Control and Decision Conference (CCDC), 2016.

[7] HakJoon Kim and Bangwoo Han, "Model of air purifier using an activated carbon fibre", IEEE Transactions on Industry Applications, August 2017.

[8] Alexi Delgado and Hugo Flor, "To select the best air purifier using AHP", CHILEAN Conference on Electrical, Electronics Engineering, Information and Communication Technologies (CHILECON), 2017.

[9] Manisha Sharma and Ajay Kumar, "I2P air purifier with air quality monitoring device", 2nd International Conference on Communication and Electronics Systems (ICCES), 2017.

[10]Xiao Qijun and Liu Chauying, "Design of control system for an intelligent air purifier and sweeper combined robot",12th IEEE Conference on Industrial Electronics and Applications (ICIEA), 2017.

[11] Sanjay Shitole and Devika Nair, "Internet of Things (IOT) based indoor air quality improving System", 3rd International Conference for Convergence in Technology (I2CT), 2018.

[12] Kennedy Okokpujie, EtinosaNoma-Osaghae, "Air pollution monitoring system", International Journal of Civil Engineering and Technology, September 2018.

[13] Chun-Ming, Yi-Jun Liu, "Model for air quality monitoring by a wireless multi-gas sensing system", IEEE International Conference on Applied System Invention (ICASI), 2018.

[14] Tanya Nanaiah and K Ambika, "EnviDron' to purify air", Second International Conference on Green Computing and Internet of Things (ICGCIoT), 2018.

[15] Marin BerovMarinov, DimitarLlive, "Portable air purifier (PAP) with Air Quality Monitoring Sensor", Proc. XXVIII International Scientific Conference Electronics - ET 2019, September, 2019. 